https://helda.helsinki.fi

\title{
The emergence of private land conservation in scientific literature: a review
}

\section{Cortes Capano, Gonzalo}

2019-09

Cortes Capano , G , Toivonen , T, Soutullo , A \& Di Minin , E 2019 , ' The emergence of private land conservation in scientific literature: a review ' , Biological Conservation, vol. 237 , pp. 191-199 . https://doi.org/10.1016/j.biocon.2019.07.010

http://hdl.handle.net/10138/332350

https://doi.org/10.1016/j.biocon.2019.07.010

cc_by_nc_nd

acceptedVersion

Downloaded from Helda, University of Helsinki institutional repository.

This is an electronic reprint of the original article.

This reprint may differ from the original in pagination and typographic detail.

Please cite the original version. 


\section{The emergence of private land conservation in scientific literature: a review}

2

3 Keywords: Biodiversity; conservation easements; conservation actions; policy instruments; private 4 land conservation; stakeholders.

5 Type of article: review article

\section{Abstract}

8 Private land conservation (PLC) is an important means for achieving global conservation targets.

9 We reviewed peer-reviewed literature focussing on PLC to summarize past scientific evidence and to identify research trends and gaps to direct future research. We carried out an in-depth review of 284 scientific articles and analysed where, when and in what context PLC has been studied. Specifically, we (i) assessed where and when PLC studies took place and which topics they covered; (ii) identified the most addressed conservation actions and policy instruments, and (iii) investigated whether stakeholders' engagement during research processes was reported or not. We found that (i) there has been an increase in the number of scientific PLC publications over time; (ii) $78 \%$ of the articles in scientific journals focussed on four countries only (United States of America,

17 Australia, South Africa and Canada); (iii) literature content focussed mostly on easements, programs and landowners and showed both geographical and temporal differences; (iv) land/water protection, law and policy and livelihood, economic and other incentives were the most addressed conservation actions; (v) property rights, particularly conservation easements, were the most addressed policy instrument; and (vi) half of the articles did not report the engagement of any stakeholder sector and cross-sector stakeholders' engagement was often missing. Overall, our results highlight the need for future studies on PLC to cover currently underrepresented regions; to assess the effectiveness of more conservation actions and policy instruments; and to test how 
engaging different stakeholders can potentially promote legitimate and equitable PLC policies across contexts.

\section{Introduction}

Aichi target 11 of the Convention of Biological Diversity promotes the expansion of the global protected area network to cover at least $17 \%$ of all terrestrial land by 2020 , while enhancing ecological representativeness and connectivity (Convention on Biological Diversity [CBD], 2010). With limited resources available for protected area expansion and effective management, meeting Aichi target 11 requires countries to design and implement complementary area-based conservation policies (CBD 2010).

With privately owned land covering large areas of the world, private land conservation (PLC) is an increasingly recognized strategy to complement protected area networks, either as privately protected areas (PPAs, i.e. areas that have a primary conservation objective) or as 'other effective area-based conservation measures' (i.e. areas that deliver the effective in-situ conservation of biodiversity, regardless of its primary objectives) (Bingham et al., 2017; Kamal et al., 2015b; Mitchell et al., 2018; Stolton et al., 2014; WCPA, 2019). As the field is complex and continuously growing, the semantics and governance systems of PLC include multiple definitions (e.g. Stolton et al. 2014; Kamal et al. 2015b). In this article, we broadly refer to PLC as land under private ownership (e.g. individuals, families or other non-public institutions) managed to help achieve biodiversity conservation objectives. PLC policies have the potential to (i) increase total area under protection, (ii) increase the diversity of stakeholders engaged in conservation policy-making, (iii) enhance ecological and socio-economic connectivity and (iv) reduce social conflict (Doremus, 2003; Maciejewski et al., 2016; Paloniemi and Tikka, 2008; Stolton et al., 2014; Wallace et al., 2008). However, designing effective national and sub-national (e.g. municipal) PLC policies is 
challenging, as it requires interacting with complex, context dependent socio-ecological, institutional, legal and economic processes (Cocklin et al., 2007; Doremus, 2003; Kamal et al., 2015a; Selinske et al., 2017).

Implementing on the ground conservation actions on private land mostly depends on landowners' willingness to collaborate with conservation organizations (e.g. in terms of enrolment, permanence and security of conservation agreements) and their management capabilities (e.g. in terms of resources and knowledge) (Farmer et al., 2017; Hardy et al., 2017; Knight et al., 2010; Selinske et al., 2015). In addition, the success of PLC depends on conservation organizations capacities to adequately plan, implement and monitor the effectiveness of conservation actions (Clement et al., 2015; Drescher and Brenner, 2018; Epstein et al., 2015; Rissman et al., 2017). In this context, many policies involving a wide range of instruments have been developed worldwide to increase landowners' engagement in PLC, to support them with implementing conservation actions, and to ensure their long-term commitment (Casey et al., 2006; Selinske et al., 2015). These range from involuntary policies, which might include imposed land use regulations, to voluntary policies, which can include financial and capacity building instruments (Casey et al., 2006; Disselhoff, 2015; Kamal et al., 2015b). Overall, the success of PLC policies depends on designing and implementing a suite of different policy instruments according to geographical contexts and to the needs, values, and capabilities of different stakeholders (Cocklin et al., 2007; Doremus, 2003; Selinske et al., 2017).

Engaging stakeholders in conservation research and policy-making processes has been considered critical to adequately address complex science-implementation spaces (e.g. Reed et al. 2009; Sterling et al. 2017; Toomey et al. 2017). As a result, a growing number of international conventions and science-policy platforms call for stakeholders' engagement as a way of facilitating 
the co-production of relevant and usable knowledge (e.g. CBD, Intergovernmental Platform for Biodiversity and Ecosystem Services [IPBES], Future Earth; van der Hel 2016; Tengö et al. 2017). Engaging stakeholders in a comprehensive way (e.g. by conducting stakeholder analyses, Reed et al., 2009) is seen particularly important in the context of PLC research that aims to inform policymaking because a wide range of community, business and government stakeholders might be interested or affected by the implementation of PLC policies (Cocklin et al., 2007; Cooke et al., 2012; Kamal and Grodzinska-jurczak, 2014; Paloniemi et al., 2018).

As several governments are currently developing and implementing different PLC policies to achieve national and global conservation targets (Disselhoff, 2015; Stolton et al., 2014; WCPA, 2019), there is a clear need to assess the published scientific literature, identify research gaps, and direct future research. To our knowledge, no previous literature review has studied research trends and gaps in PLC peer-reviewed literature at the global level (but see for example Casey et al. 2006; Stolton et al. 2014; Disselhoff 2015; Kamal et al. 2015b, for PLC policy instruments descriptions and classifications). Here, we filled this gap and (i) assessed when and where the identified studies took place and which topics they covered; (ii) identified the most addressed conservation actions and policy instruments, and (iii) investigated whether stakeholders' engagement during research processes was reported or not. For the purpose of this review, we focused on the broader PLC literature, including literature on PPAs as well as other PLC policies. Finally, we discuss possible ways for future PLC research to fill the gaps in order to better inform PLC policy-making and to increase on the ground outcomes.

\section{Methods}

We conducted a comprehensive keyword search in SCOPUS database, capturing articles published between 1988 to February 2018. We used the following keyword search: (TITLE-ABS-KEY 
("Private land Conservation" OR "Private Reserves" OR "Private* Protected Areas" OR "Private

101

102

103

104

105

106

107

108

109

110

111

112

113

114

115

116

117

118

119

120

121

122

123

conservation areas" OR "Private Game Reserves" OR "Private Wildlife Reserves" OR "Private

Wildlife Refuges" OR "Private Nature Reserves" OR "voluntary conservation" OR "conservation

easements" OR “conservation covenants")). As PLC terminology can be context-dependent, we

included other widely used broad synonyms for PLC in different countries and regions (e.g. private game reserve, conservation easements). While we are aware that there are many PLC policies and topics addressed in the "grey literature" (e.g. local and national reports) and that scientific documents on biodiversity conservation are also published in other languages than English (Amano et al., 2016), in this study we only focussed on peer-reviewed articles in English. This choice was due to the global nature of this study and the potential geographical and language bias in accessing and interpreting national and local reports.

Our initial search resulted in 858 articles. We read all abstracts to ensure inclusion of relevant articles only. We considered an article relevant for our review if it described PLC policies, policy instruments, actions, and/or analysed their effectiveness and impacts on biodiversity conservation. We discarded articles focussing on reporting ecological surveys inside PLC areas without relating the results to PLC policies or those articles focussing on agriculture policies without addressing their potential impact on biodiversity conservation.

After manual sorting, our final database resulted in 284 articles (264 research articles, 16 reviews, two letters and two notes, according to Scopus document type classification) (see Appendix A for a full list). After reading the whole text, for each study we recorded (i) year of publication, (ii) countries where the studies were conducted, (iii) conservation actions and policy instruments addressed, and (iv) stakeholder sectors reported to be engaged during the research process. Some 
studies were from several countries and/or addressed more than one policy instrument and were classified accordingly.

126

127 We then carried out a content analysis to identify most frequent words (hereafter topics, according to our content interpretation) present only in articles' abstracts, using the tm package (Feinerer and

129 Hornik, 2017) in R version 3.4.4 (R Core Team 2018). We also counted the number of abstracts that use these most frequent topics. In order to concentrate on the relevant policy related content, we removed frequent English "stop words" (e.g. the, is, what, we) from the analysis. We removed the term "private land conservation" because it was already the focus of our review and might have obscured the relationship between other words. We then classified the articles according to the date when they were published. We used year 2010, when the Strategic Plan for Biodiversity 2011-2020 and the Aichi Biodiversity Targets were approved (CBD 2010), as a policy landmark that could have affected the temporal trends in PLC research content. In addition, we classified the abstracts' content per continent where the studies were conducted to detect geographical content patterns. We also searched for unique topics within the most frequently addressed topics (i.e. ten most frequent topics) to detect other patterns at geographical and temporal levels. While it is important to note that we have only analysed text from articles' abstracts, abstracts should nonetheless report the most relevant concepts from the entire articles. Therefore, we argue that analysing the whole text would not greatly affect our main results (Nunez-mir et al., 2015).

In order to assess which conservation actions were addressed or recommended in the articles to increase the effectiveness of PLC policies, we followed the classification by Salafsky et al. (2008). Conservation actions can be defined as interventions undertaken by different stakeholders, designed to reach conservation goals (Salafsky et al., 2008). We then classified conservation actions as: (i) land/water protection, i.e. those actions that identify, establish or expand legally protected areas, 
and those that protect resource rights; (ii) land/water management, i.e. those actions that aim to conserve or restore habitats and the environment in general; (iii) species management, i.e. those

151

152 actions focussed on managing or restoring species; (iv) education and awareness, i.e. those actions directed at improving people's understanding and skills; (v) law and policy, i.e. those actions that help develop and implement legislation, regulations, and voluntary standards; (vi) livelihood, economic and other incentives, i.e. those actions developed and implemented to influence behaviour; and (vii) external capacity building, i.e. those actions aiming to facilitate the conditions to increase conservation impact.

In the context of this review, we followed Game et al. (2015) definition of conservation policies, to be any set of institutionalized behaviours or practices that influence conservation activities. PLC policies typically consist of a set of different policy instruments, which can be defined as any type of instrument designed to support or promote a change in behaviour (induced or voluntary), associated with biodiversity conservation on private land (Casey et al., 2006; Disselhoff, 2015; Doremus, 2003; Selinske et al., 2017). We classified the policy instruments addressed in the articles following the classification by Casey et al. (2006). We used this taxonomy because it is comprehensive and broad enough to include a wide variety of policy instruments developed to promote PLC (Casey et al., 2006). We classified policy instruments as: (i) regulatory \& economic disincentives: policies that discourage practices that might have negative impacts on biodiversity, by defining management standards and penalties for non-compliance; (ii) legal/statutory innovations: new rules that provide some permits for ecosystem transformations or regulatory relief for those landowners who voluntary commit to implement conservation actions on their properties; (iii) property rights instruments: involve landowners voluntarily transferring total or partial property rights to a conservation organization (e.g. land trust, government agency) in order to restrict land use intensity; (iv) market based instruments: developed to create markets that value 
174 biodiversity conservation, increasing economic opportunities for landowners through the design of

175 certification schemes or ecotourism; (v) financial instruments: involve payments to compensate

176 landowners for the opportunity and/or management costs associated with implementing

177 conservation actions on their land; (vi) public tax instruments: provide tax reductions (e.g. income,

178 property) to those landowners who maintain or restore land for biodiversity; (vii) facilitative

179 instruments: institutional strategies designed to build landowners' capacity to implement

180 conservation actions, by providing training, technical assistance and recognition of conservation

181 efforts among other benefits.

182

183 In order to assess which stakeholder sectors were reported to be engaged in PLC research we

184 followed the classification suggested by the United Nations Development Programme (UNDP

185 2012). The classification recognizes the following types of stakeholder sectors: private (e.g.

186 individuals, families, businesses), public (e.g. national and local governments, international bodies)

187 and civil society (e.g. media, universities, NGOs). Then, to determine whether a given stakeholder

188 sector was reported to be engaged, we used Rowe \& Frewer (2000) stakeholders' engagement

189 classification, which is based on the direction of communication between parties. It recognizes three

190 broad categories: (i) communication (i.e. dissemination to passive recipients), (ii) consultation (i.e.

191 collecting information from participants) and (iii) participation (i.e. two-way communication and

192 learning process between participants and researchers) (Rowe and Frewer, 2000). Within the scope

193 of this review, we broadly considered that a stakeholder sector was engaged in the research process

194 if the paper documented (i) consultation or (ii) participation engagement (e.g. interviews, surveys, 195 workshops).

197 3. Results 
198 Our results showed an increasing temporal trend in the number of published peer-reviewed articles

199 in English focussing on PLC (see Appendix B, Fig. B1). The number has, in fact, doubled after 2002010 when the Strategic Plan for Biodiversity 2011-2020 and the Aichi Biodiversity Targets were 201 approved (CBD 2010). However, the number of articles appears to have stabilized in the last years 202 (Fig. B1). Furthermore, we found a strong geographic bias in the English peer-reviewed literature 203 (Fig. 1). Research in the analysed 284 articles was conducted in 26 countries (15 studies were either

204 theoretical or analysed different aspects of PLC policies without focussing on any particular 205 region). Most studies (78\%) were conducted only in four countries, namely United States of America (U.S.A) (56\%, N=155); Australia (12\%, N=33); South Africa (6\%, N=16); and Canada $(4 \%, \mathrm{~N}=12)$. Asia was the least represented continent with only one study conducted in Indonesia. In Europe, the most represented country was Finland (3\%, N=7). In Latin America \& the Caribbean the most represented country was Brazil (3\%, N=7). In Africa, the second most represented country after South Africa was Kenya (2\%, N=6).

The most frequent topics covered in the abstracts were "easement(s)", which was mentioned 508 times in 125 abstracts, "landowner(s)" which got 329 mentions in 138 abstracts, and "program(s)" that was mentioned 326 times in 125 abstracts (see Appendix C, Table C1). Other important topics were "management" ( $\mathrm{f}=202,91$ abstracts) and "protect" ( $\mathrm{f}=175,47$ abstracts). Other topics such as “institution(s), or (institutional)" (f=41), "sustainability (or sustainable)" (f=34), "governance" $(\mathrm{f}=15)$ and "well-being" ( $\mathrm{f}=3)$, were less present in the abstracts.

Regarding temporal patterns in abstracts content, the three most frequent topics in PLC literature (easement, program and landowner, Fig. 2, see Table $\mathrm{C} 1$ for full details) were present both before 
$(\mathrm{f}=55)$ and "use (e.g. use of biodiversity)" $(\mathrm{f}=52)$ received more attention, whereas after CBD Aichi

targets literature mostly focussed on issues regarding "property" ( $\mathrm{f}=115)$, "forest" $(\mathrm{f}=106)$, "policy" (f=102) and "participation" (f=101) (Table C1).

We also found geographical differences in PLC abstracts content (Fig. 3, see Table C2 for full details). In North America, the most common topics were "easement" (f=493), "landowner" ( $\mathrm{f}=246)$ and "program" ( $\mathrm{f}=193$ ). Latin America and the Caribbean literature mostly focussed on topics such as "reserve" ( $\mathrm{f}=87)$, "protect" $(\mathrm{f}=36)$ and "incentive" ( $\mathrm{f}=22)$, whereas in Africa the most frequent topics were "management" (f=41), "protect" ( $f=34)$ and "species" ( $f=26)$. The most prominent topics in the abstracts from Europe were "landowner" ( $\mathrm{f}=53)$, "program" $(\mathrm{f}=36)$ and "voluntary" ( $\mathrm{f=34})$. In the case of Oceania, the most frequent topics were "program" $(\mathrm{f}=77)$, "landholder" ( $\mathrm{f}=63$ ) and "management" $(\mathrm{f}=45)$. We did not include the results from Asia because only one article was found. In addition, we found unique topics within the most frequently addressed topics per continent (i.e. ten most frequent topics), for example "public" in North America, "ecotourism" in Latin America and the Caribbean, "species" in Africa, "voluntary" in Europe, and "benefit" in Oceania.

\section{Regarding conservation actions, all articles in our database addressed or discussed land/water} protection actions $(100 \%, \mathrm{~N}=284)$, followed by law and policy conservation actions $(88 \%, \mathrm{~N}=251)$, conservation actions related to livelihood, economic and other incentives (75\%, N=213), land/water management $(45 \%, \mathrm{~N}=128)$, external capacity building ( $32 \%, \mathrm{~N}=91)$, species management ( $15 \%$, $\mathrm{N}=43)$, and education and awareness $(14 \%, \mathrm{~N}=41)$. We also found that English peer-reviewed literature in different continents generally reflected these global patterns, with the exception of Africa, where incentives and land/water management were the most addressed actions, following 
247 land conservation actions (see Fig. D1). Education and awareness conservation actions were the

248 least addressed actions across all continents (see Fig. D1).

Regarding the policy instruments addressed in the articles, property rights, particularly conservation

251

252

253

254

255

256

257

258

259

260

261

262

263

264

265

266

267

268

269

270

271

easements, were the most covered policy instrument accounting for $73 \%$ of the studies $(\mathrm{N}=207)$,

followed by financial instruments (e.g. cost-share incentives; 37\%, N=105), and market-based instruments (e.g. ecotourism and certification schemes; 30\%, N=84) (Fig. 4). The least addressed policy instruments were regulatory and economic disincentives $(8 \%, \mathrm{~N}=22)$ and legal/statutory innovations $(5 \%, \mathrm{~N}=13)$. We found geographical differences in the number of English peerreviewed articles addressing different policy instruments in different continents (Fig. D2). In North America and Oceania, property rights were the most addressed policy instruments. In Latin America and the Caribbean and in Africa, market-based instruments received more attention, whereas in Europe financial instruments were the most addressed instruments.

In relation to stakeholder sectors engagement, no stakeholders were reported to be engaged in $48 \%$ of the PLC studies (N=138; Fig. 5a). Furthermore, we found that only one sector was reported to be engaged in $38 \%$ of the studies $(\mathrm{N}=107)$. Within those articles that reported to engage only one stakeholder sector, the private sector was the most engaged $80 \%(\mathrm{~N}=86)$, followed by the civil society sector $17 \%(\mathrm{n}=18)$ and the public sector with only $3 \%(\mathrm{~N}=3)$. Similarly, within those articles that reported to engage at least one stakeholder sector $(52 \%, \mathrm{~N}=149)$, we found that private sector (e.g. landowners) was involved in $79 \%$ of the studies $(\mathrm{N}=118)$, followed by the civil society sector (e.g. NGOs; 36\%, N=54) and the public sector (e.g. governments; 26\%, N=39) (Fig. 5b). Overall, cross-sector engagement was unusual in our database, with only few articles reporting the engagement of two $(8 \%, \mathrm{~N}=22)$ or three $(7 \%, \mathrm{~N}=20)$ stakeholder sectors (Fig 5a). The number of English peer-reviewed articles reporting stakeholders' engagement in each continent broadly 
272 reflected these global patterns, except for studies conducted in Europe where private and the public

273 sectors were the most reported stakeholders (Fig. D3).

274

275

\section{Discussion}

276

277

278

279

280

281

282

283

284

285

In this paper, we reviewed the PLC literature to identify important research trends and gaps. Our results showed (i) an increase in the number of PLC publications over time, followed by a period of stagnation after 2010; (ii) a strong geographical bias with most scientifically published research conducted in four countries only, particularly the U.S.A.; (iii) that the literature content broadly focussed on easements, programs, landowners and management, and that there were both geographical and temporal content patterns; (iv) that literature mostly focussed on addressing conservation actions related to land/water protection, to law and policy and to livelihood, economic and other incentives; (v) that property rights were the most addressed PLC policy instruments; and (vi) that almost half of the studies did not report any stakeholder sector engagement in research and that engaging more than one stakeholder sector was infrequent. While we are aware that there is an important amount of information about PLC policies and implementation in grey literature, our results nonetheless reflect important PLC trends and gaps and the way key issues are currently covered in peer-reviewed literature.

Although PLC has a long history in some countries, formal international recognition came only recently and only for some PLC policies (e.g. PPAs, other effective area-based conservation measures; Bingham et al., 2017; Mitchell et al., 2018; Stolton et al., 2014; WCPA, 2019). In this sense, the increasing scientific publication trend is in accordance with the growing recognition of the importance of PLC policies to achieve biodiversity and ecosystem services conservation targets (Bingham et al., 2017; Stolton et al., 2014). 
Regarding the geographical distribution of research, it is not surprising that the U.S.A., Australia,

298 South Africa and Canada were the most represented countries in the literature given that they have long PLC tradition (Fitzsimons, 2015; Maciejewski et al., 2016; Merenlender et al., 2004; Schuster et al., 2017). We acknowledge that, in spite of our efforts, our results might be biased to a certain level because we only considered peer-reviewed articles written in English, while the topic might well be covered in other languages (Amano et al., 2016) and PLC be an important topic of discussion also in other countries. Nonetheless, the fact that only $\sim 20 \%$ of the reviewed studies were conducted in other countries around the world reveals the existence of an important geographical bias in English peer-reviewed studies related to PLC. Therefore, considering that most processes involved in PLC are typically context dependent, it is important to be cautious when transferring evidence and recommendations from current English peer-reviewed literature to policymaking in other countries (Cooke et al., 2012). In order to fill this gap and to understand how variations in local contexts might influence policy outcomes, there is need to conduct more internationally recognised scientific research in different underrepresented geographical regions where land is mostly privately owned (Cetas and Yasué, 2016; Cooke et al., 2012; Selinske et al., 2017; Sorice and Donlan, 2015).

In terms of research focus at the global level, there was a clear emphasis in literature content on conservation easements as instruments to promote the conservation of both land and threatened species. Understanding landowners' motivations and preferences to place an easement or to join other PLC programs was another major research focus. Although these topics are relevant, it would be important to conduct more research assessing the contribution of PLC to socio-ecological systems sustainability and human well-being (e.g. Wallace et al. 2008; Villamagna et al. 2015; 
Regarding temporal trends in content, even though the most frequent topics present in the abstracts were similar before and after CBD Aichi targets (easements, programs and landowners), a closer look into high frequency unique topics showed different emphasis in content. For example, while before Aichi targets reserves and incentives were frequently mentioned in abstracts, after Aichi targets topics such as property, policy and participation became more prevalent. In the context of having to meet national and international targets for biodiversity conservation with limited resources, literature focus has shifted from a focus on general biodiversity conservation programs (e.g. species conservation, land use restrictions, Langholz, 1996; Merenlender et al., 2004; Swift et al., 2004; Wright, 1994) to studying national and international policies, and the broad set of instruments and requirements to comply with them (e.g. Adams and Moon, 2013; Barton et al., 2013; Cooke and Moon, 2015; Drescher et al., 2017; Owley and Rissman, 2016).

Research from different continents focussed on different topics. This geographical heterogeneity in PLC literature topics and focus might be influenced to a certain extent by researchers' interests, but might well also reflect research adaptation to regional contexts (i.e. related to the types of existing policies in each region). In Latin America \& the Caribbean, PLC literature mostly focussed on addressing issues related to nature reserves, different incentives to increase landowners' enrolment and ecotourism. Focus on these topics was mainly driven by literature from Brazil, where private reserves in perpetuity are legally recognized and can only be used for research, education and ecotourism (Pegas and Castley, 2016, 2014). In the case of PLC literature from Africa, the content was largely driven by studies conducted in South Africa, addressing issues related to endangered and charismatic species management and protection (e.g. Maciejewski and Kerley, 2014). Social aspects of PLC planning were also addressed in literature from Africa (e.g. Knight et al., 2010; Pasquini et al., 2010). Literature from Europe mostly focussed on issues related to landowners' attitudes and preferences and on voluntary programs (e.g. Kamal et al., 2015c; Mönkkönen et al., 
2009; Nielsen et al., 2018). Finally, literature from Oceania was mostly driven by Australia and

348 broadly focussed on addressing landowners' motivations, programs design and land management

349 (e.g. Adams et al., 2014; Greiner, 2015; Moon and Cocklin, 2011). This literature content

350 heterogeneity contributes to the identification of regional needs and opportunities to increase PLC

351 impact on the ground.

352

353 Regarding conservation actions, our results showed that the most addressed actions in PLC peer-

354 reviewed literature were land conservation, law and policy and actions related to livelihood,

355 economic and other incentives. These findings were to a certain extent expected, given the

356 importance of these actions in the context of PLC. Although these results were largely influenced

357 by research conducted in North America, it is interesting to note that English peer-reviewed

358 literature in different continents generally reflected these patterns, except in Africa, where

359 incentives and land management actions received comparatively more attention. Overall, most of

360 the literature focussed on landowners' motivations and barriers to participation while less than half

361 of the peer-reviewed articles addressed or discussed about management actions implementation and

362 effectiveness after enrolment (Farmer et al., 2017). This gap might be partially caused by

363 conservation easements generally focussing on restricting development and preventing land use

364 change rather than on fostering stewardship and adaptive management (Rissman et al., 2013;

365 Rissman, 2013). Although attention towards addressing management actions has increased recently

366 (e.g. Adams et al., 2012; Farmer et al., 2017; Hardy et al., 2017; Rissman, 2010; Stroman and

367 Kreuter, 2015), there is still need to conduct more studies in different geographical contexts.

368 Research on other key conservation actions such as external capacity building (e.g. Clement et al.,

369 2015), species management (e.g. Maciejewski and Kerley, 2014), and education and awareness (e.g.

370 Van Fleet et al., 2012) was consistently underrepresented both at the global and continental levels.

371 Efforts should be made to fill these gaps, both in order to build a more comprehensive PLC science 
372 framework, and to understand how to better combine different conservation actions to increase PLC

373 effectiveness on the ground.

374

375 Regarding policy instruments, we found that property rights, particularly conservation easements

376 and covenants, were the most addressed instruments at the global level (e.g. Merenlender et al.

377 2004; Rissman et al. 2007; Fitzsimons \& Carr 2014; see Nolte, 2018 for a recent in-depth review

378 on acquisition of private forest property rights for conservation). While the proportion of

379 investments on property rights acquisitions has grown exponentially in the last decades (Fishburn et

380 al., 2009), comprehensive evidence on their long-term effectiveness is still relatively limited (Braza,

381 2017; Byrd et al., 2009; Copeland et al., 2013; Hardy et al., 2017; Merenlender et al., 2004;

382 Pocewicz et al., 2011; Rissman et al., 2007). In addition, as easements are becoming increasingly

383 international, there is need to assess their implementation feasibility in different countries where

384 resources for conservation are limited, either to buy property rights or to bear the loss of revenue

385 from taxes (Kamal et al., 2015b). Furthermore, there is an urgent need to assess their implications

386 for different socio-political contexts, particularly regarding effectiveness of public expenditure,

387 transparency and equity (Cooke and Corbo-Perkins, 2018; Rissman et al., 2017). Future research

388 should aim at addressing a broader set of policy instruments, which might be relevant in

389 geographical areas not yet covered in English peer-reviewed literature and at identifying general

390 aspects of PLC policy design that could enhance effectiveness across contexts (Cocklin et al., 2007;

391 de Vente et al., 2016; Moon and Cocklin, 2011).

393 Despite the recent emphasis on stakeholders' engagement in conservation research (Reed et al.

394 2009; Sterling et al. 2017; Toomey et al. 2017), almost half of the PLC studies did not report any stakeholder sector engagement in their research processes. The private sector was the most engaged stakeholder group (mostly through consultation, e.g. surveys, interviews), not only at the global 
level but also at the continental level. This finding was expected according to the key role private

398 sector plays in PLC policies implementation (Farmer et al., 2017; Knight et al., 2010; Moon and

399 Cocklin, 2011). However, research would also benefit from increasingly engaging other

400

401

402

403

404

405

406

407

408

409

410

411

412

413

414

415

416

417

stakeholders, such as the public sector, who might be key for supporting, recognizing and reporting private initiatives to comply with international conventions such as the CBD (Bingham et al., 2017). We also found that reporting cross-sector stakeholders' engagement was infrequent.

Integrating different stakeholders' perspectives into research and decision-making depends on the research question and can be challenging due to issues such as legitimacy, power relations and conflicting interests (Reed et al., 2009). However, actively and comprehensively engaging different stakeholders following co-production approaches could potentially lead to (i) more innovative research, (ii) increasingly shared understanding of complex socio-ecological systems, and (iii) the formulation of more legitimate and actionable policy proposals (Beier et al., 2017; Bracken et al., 2015; de Vente et al., 2016; Jolibert and Wesselink, 2012; Paloniemi et al., 2018; Salomaa et al., 2016). While we acknowledge that stakeholders' engagement in research might not always be fully documented in peer-reviewed articles (Jolibert and Wesselink, 2012), we call for better documentation to increase future learning opportunities.

To conclude, our results highlight the need for future studies on PLC to aim at (i) improving our understanding of diverse socio-ecological contexts and how they influence PLC policy outcomes, (ii) assessing the implementation feasibility and effectiveness of different conservation actions, particularly land management, (iii) covering a broader set of policy instruments, (iv) engaging different stakeholders in research to co-produce actionable knowledge, and (v) identifying general principles that might inform the design, governance and implementation of effective, legitimate and equitable PLC policies across contexts. 


\section{References}

423 Adams, V.M., Moon, K., 2013. Security and equity of conservation covenants: Contradictions of 424 private protected area policies in Australia. Land use policy 30, 114-119.

425 https://doi.org/10.1016/j.landusepol.2012.03.009

426 Adams, V.M., Pressey, R.L., Stoeckl, N., 2014. Estimating landholders’ probability of participating

427

428

429

430

431

432

433

434

435

436

437

438

439

440

441

442

443

444 in a stewardship program, and the implications for spatial conservation priorities. PLoS One 9. https://doi.org/10.1371/journal.pone.0097941

Adams, V.M., Pressey, R.L., Stoeckl, N., 2012. Estimating land and conservation management costs : The first step in designing a stewardship program for the Northern Territory. Biol. Conserv. 148, 44-53. https://doi.org/10.1016/j.biocon.2012.01.064

Amano, T., Gonzalez-Varo, J.P., Sutherland, W.J., 2016. Languages Are Still a Major Barrier to Global Science. PLoS Biol. 14, e2000933. https://doi.org/10.1371/journal.pbio.2000933

Barton, D.N., Blumentrath, S., Rusch, G., 2013. Policyscape-A Spatially Explicit Evaluation of Voluntary Conservation in a Policy Mix for Biodiversity Conservation in Norway. Soc. Nat. Resour. 26, 1185-1201. https://doi.org/10.1080/08941920.2013.799727

Beier, P., Hansen, L.J., Helbrecht, L., Behar, D., 2017. A How-to Guide for Coproduction of Actionable Science. Conserv. Lett. 10, 288-296. https://doi.org/10.1111/conl.12300

Bingham, H., Fitzsimons, J.A., Redford, K.H., Brent, A., Bezaury-creel, J., Cumming, T.L., 2017. Privately Protected areas: advances and challenges in guidance, policy and documentation. Parks 23, 13-28.

Bracken, L.J., Bulkeley, H.A., Whitman, G., 2015. Transdisciplinary research : understanding the stakeholder perspective. J. Environ. Plan. Manag. 58, 1291-1308. https://doi.org/10.1080/09640568.2014.921596

Braza, M., 2017. Effectiveness of conservation easements. Conserv. Biol. 31, 848-859. https://doi.org/10.1111/cobi.12909 
Byrd, K.B., Rissman, A.R., Merenlender, A.M., 2009. Landscape and Urban Planning Impacts of

448

449

450

451

452

453

454

455

456

457

458

459

460

461

462

463

464

465

466

467

468

469

470

471 conservation easements for threat abatement and fire management in a rural oak woodland landscape. Landsc. Urban Plan. J. 92, 106-116. https://doi.org/10.1016/j.landurbplan.2009.03.003

Casey, F., Vickerman, S., Hummon, C., Bruce, T., 2006. Incentives for Biodiversity Conservation : An Ecological and Economic Assessment. Defenders of Wildlife, Washington D.C., USA.

Cetas, E.R., Yasué, M., 2016. A systematic review of motivational values and conservation success in and around protected areas. Conserv. Biol. 31, 203-212. https://doi.org/10.1111/cobi.12770

Clement, S., Moore, S.A., Lockwood, M., Mitchell, M., 2015. Using insights from pragmatism to develop reforms that strengthen institutional competence for conserving biodiversity. Policy Sci. 48, 463-489. https://doi.org/10.1007/s11077-015-9222-0

Clements, H.S., Cumming, G.S., 2017. Manager strategies and user demands: Determinants of cultural ecosystem service bundles on private protected areas. Ecosyst. Serv. 28, 228-237. https://doi.org/10.1016/j.ecoser.2017.02.026

Cocklin, C., Mautner, N., Dibden, J., 2007. Public policy, private landholders : Perspectives on policy mechanisms for sustainable land management. J. Environ. Manage. 85, 986-998. https://doi.org/10.1016/j.jenvman.2006.11.009

Cooke, B., Corbo-perkins, G., 2018. Co-opting and resisting market based instruments for private land conservation. Land use policy 70, 172-181. https://doi.org/10.1016/j.landusepol.2017.10.027

Cooke, B., Langford, W.T., Gordon, A., Bekessy, S., 2012. Social context and the role of collaborative policy making for private land conservation. J. Environ. Plan. Manag. 55, 469485. https://doi.org/10.1080/09640568.2011.608549

Cooke, B., Moon, K., 2015. Aligning “public good" environmental stewardship with the landscapescale: Adapting MBIs for private land conservation policy. Ecol. Econ. 114, 152-158. 

https://doi.org/10.1016/j.ecolecon.2015.03.027

473 Copeland, H.E., Pocewicz, A., Naugle, D.E., Griffiths, T., Keinath, D., Evans, J., Platt, J., 2013. $474 \quad$ Measuring the Effectiveness of Conservation : A Novel Framework to Quantify the Benefits of 475 Sage-Grouse Conservation Policy and Easements in Wyoming. PLoS One 8, e67261. https://doi.org/10.1371/journal.pone.0067261

477 478 479 480

481 482 483 484 485 486 487 488 489 490 491 492 493 494 495 496

de Vente, J., Reed, M.S., Stringer, L.C., Valente, S., Newig, J., 2016. How does the context and design of participatory decision making processes affect their outcomes? Evidence from sustainable land management in global drylands. Ecol. Soc. 21, 24. https://doi.org/10.5751/ES08053-210224

Disselhoff, T., 2015. Alternative Ways to Support Private Land Conservation. Berlin, Germany.

Doremus, H., 2003. A policy portfolio approach to biodiversity protection on private lands 6, 217232. https://doi.org/10.1016/S1462-9011(03)00036-4

Drescher, M., Brenner, J.C., 2018. The practice and promise of private land conservation. Ecol. Soc. 23,3 .

Drescher, M., Keith Warriner, G., Farmer, J.R., Larson, B.M.H., 2017. Private landowners and environmental conservation: A case study of social-psychological determinants of conservation program participation in Ontario. Ecol. Soc. 22. https://doi.org/10.5751/ES09118-220144

Epstein, G., Pittman, J., Alexander, S.M., Berdej, S., Dyck, T., Kreitmair, U., Rathwell, K.J., Villamayor-tomas, S., Vogt, J., Armitage, D., 2015. Institutional fit and the sustainability of social - ecological systems. Curr. Opin. Environ. Sustain. 14, 34-40. https://doi.org/10.1016/j.cosust.2015.03.005

Farmer, J.R., Ma, Z., Drescher, M., Knackmuhs, E.G., Dickinson, S.L., 2017. Private Landowners, Voluntary Conservation Programs, and Implementation of Conservation Friendly Land Management Practices. Conserv. Lett. 10, 58-66. https://doi.org/10.1111/conl.12241 
497 Feinerer, I., Hornik, K., 2017. tm: Text Mining Package. R package version 0.7-3.

498 Fishburn, I.S., Kareiva, P., Gaston, K.J., Armsworth, P.R., 2009. The Growth of Easements as a Conservation Tool. PLoS One 4, e4996. https://doi.org/10.1371/journal.pone.0004996

500

501

502

503

504

505

506

507

508

509

510

511

512

513

514

515

516

517

518

519

520

521

Fitzsimons, J.A., 2015. Private protected areas in Australia : current status and future directions 23, 1-23. https://doi.org/10.3897/natureconservation.10.8739

Fitzsimons, J.A., Carr, C. Ben, 2014. Conservation Covenants on Private Land : Issues with Measuring and Achieving Biodiversity Outcomes in Australia. Environ. Manage. 54, 606-616. https://doi.org/10.1007/s00267-014-0329-4

Game, E.T., Schwartz, M.W., Knight, A.T., 2015. Policy Relevant Conservation Science. Conserv. Lett. 8, 309-311. https://doi.org/10.1111/conl.12207

Greiner, R., 2015. Motivations and attitudes influence farmers' willingness to participate in biodiversity conservation contracts. Agric. Syst. 137, 154-165. https://doi.org/10.1016/j.agsy.2015.04.005

Hardy, M.J., Fitzsimons, J.A., Bekessy, S.A., Gordon, A., 2017. Exploring the Permanence of Conservation Covenants. Conserv. Lett. 10, 221-230. https://doi.org/10.1111/conl.12243

Hardy, M.J., Fitzsimons, J.A., Bekessy, S.A., Gordon, A., 2017. Exploring the Permanence of Conservation Covenants. Conserv. Lett. 10, 221-230. https://doi.org/10.1111/conl.12243

Horton, K., Knight, H., Galvin, K.A., Goldstein, J.H., Herrington, J., 2017. An evaluation of landowners' conservation easements on their livelihoods and well-being. Biol. Conserv. 209, 62-67. https://doi.org/10.1016/j.biocon.2017.02.016

Jolibert, C., Wesselink, A., 2012. Research impacts and impact on research in biodiversity conservation: The influence of stakeholder engagement. Environ. Sci. Policy 22, 100-111. https://doi.org/10.1016/j.envsci.2012.06.012

Kamal, S., Agata, M.G., Kaszynska, P., 2015a. Challenges and opportunities in biodiversity conservation on private land : an institutional perspective from Central Europe and North 
America. Biodivers. Conserv. 1271-1292. https://doi.org/10.1007/s10531-014-0857-5

523 Kamal, S., Grodzinska-jurczak, M., 2014. Should conservation of biodiversity involve private

524

525

526

527

528

529

530

531

532

533

534

535

536

537

538

539

540

541

542

543

544

545

546

land ? A Q methodological study in Poland to assess stakeholders' attitude 2689-2704. https://doi.org/10.1007/s10531-014-0744-0

Kamal, S., Grodzińska-jurczak, M., Brown, G., 2015b. Conservation on private land: a review of global strategies with a proposed classification system. J. Environ. Plan. Manag. 58, 576-597. https://doi.org/10.1080/09640568.2013.875463

Kamal, S., Kocór, M., Grodzińska-Jurczak, M., 2015c. Conservation opportunity in biodiversity conservation on regulated private lands: Factors influencing landowners' attitude. Environ. Sci. Policy 54, 287-296. https://doi.org/10.1016/j.envsci.2015.07.023

Knight, A.T., Cowling, R.M., Difford, M., Campbell, B.M., 2010. Mapping Human and Social Dimensions of Conservation Opportunity for the Scheduling of Conservation Action on Private Land. Conserv. Biol. 24, 1348-1358. https://doi.org/10.1111/j.15231739.2010.01494.x

Langholz, J., 1996. Economics, objectives, and success of private nature reserves in Sub-Saharan Africa and Latin America. Conserv. Biol. 10, 271-280. https://doi.org/10.1046/j.15231739.1996.10010271.x

Maciejewski, K., Baum, J., Cumming, G.S., 2016. Integration of private land conservation areas in a network of statutory protected areas : Implications for sustainability. BIOC 200, 200-206. https://doi.org/10.1016/j.biocon.2016.05.027

Maciejewski, K., Kerley, G.I.H., 2014. Understanding Tourists ' Preference for Mammal Species in Private Protected Areas : Is There a Case for Extralimital Species for Ecotourism ? 9. https://doi.org/10.1371/journal.pone.0088192

Maciejewski, K., Kerley, G.I.H., 2014. Understanding tourists’ preference for mammal species in private protected areas: Is there a case for extralimital species for ecotourism? PLoS One 9. 
https://doi.org/10.1371/journal.pone.0088192

548 Merenlender, A.M., Huntsinger, L., Guthey, G., Fairfax, S.K., 2004. Land Trusts and Conservation Easements : Who Is Conserving What for Whom ? Conserv. Biol. 18, 65-75.

550

551

552

553

554

555

556

557

558

559

560

561

562

563

564

565

566

567

568

569

570

571
Mitchell, B.A., Fitzsimons, J.A., Stevens, C.M.D., Wright, D.R., 2018. PPA OR OECM? Differentiating between Privately Protected Areas and Other Effective Area - Based Conservation Measures on Private Land. Parks 24, 49-60.

Mönkkönen, M., Ylisirniö, A.-L., Hämäläinen, T., 2009. Ecological efficiency of voluntary conservation of Boreal-forest biodiversity | Eficiencia ecoĺogica de la conservacíon voluntaria de la biodiversidad de bosques boreales. Conserv. Biol. 23, 339-347. https://doi.org/10.1111/j.1523-1739.2008.01082.x

Moon, K., Cocklin, C., 2011. A Landholder-Based Approach to the Design of Private-Land Conservation Programs | Un Método Basado en Propietarios para el Diseño de Programas de Conservación en Terrenos Privados. Conserv. Biol. 25, 493-503. https://doi.org/10.1111/j.1523-1739.2010.01639.x

Moon, K., Cocklin, C., 2011. A Landholder-Based Approach to the Design of Private-Land Conservation Programs 25, 493-503. https://doi.org/10.1111/j.1523-1739.2010.01639.x

Nielsen, Anne, S.E., Bredahl, J.B., Strange, N., 2018. Landowner participation in forest conservation programs: A revealed approach using register, spatial and contract data. J. For. Econ. 30, 1-12. https://doi.org/10.1016/j.jfe.2017.10.003

Nolte, C., 2018. Buying forests for conservation: contours of a global trend. Curr. Opin. Environ. Sustain. 32, 68-75. https://doi.org/10.1016/j.cosust.2018.05.003

Nunez-mir, G.C., Iannone, B. V, Curtis, K., Fei, S., 2015. Evaluating the evolution of forest restoration research in a changing world : a "big literature" review. New For. 46, 669-682. https://doi.org/10.1007/s11056-015-9503-7

Owley, J., Rissman, A.R., 2016. Trends in private land conservation: Increasing complexity, 
shifting conservation purposes and allowable private land uses. Land use policy $51,76-84$. https://doi.org/10.1016/j.landusepol.2015.10.026

574 Paloniemi, R., Hujala, T., Rantala, S., Harlio, A., Salomaa, A., Primmer, E., Arponen, A., Pynn, S., 2018. Integrating Social and Ecological Knowledge for Targeting Voluntary Biodiversity Conservation 11, 1-10. https://doi.org/10.1111/conl.12340

577 Paloniemi, R., Tikka, P., 2008. Ecological and social aspects of biodiversity conservation on private lands. Environ. Sci. Policy 11, 336-346. https://doi.org/10.1016/j.envsci.2007.11.001

Pasquini, L., Twyman, C., Wainwright, J., 2010. Toward a Conceptual Framework for Blending Social and Biophysical Attributes in Conservation Planning : A Case-Study of PrivatelyConserved Lands 659-670. https://doi.org/10.1007/s00267-010-9548-5

582 583

584
Pegas, F.V., Castley, J.G., 2016. Private reserves in Brazil: Distribution patterns, logistical challenges, and conservation contributions. J. Nat. Conserv. 29, 14-24. https://doi.org/10.1016/j.jnc.2015.09.007

Pegas, F.V., Castley, J.G., 2014. Ecotourism as a conservation tool and its adoption by private protected areas in Brazil. J. Sustain. Tour. 22, 604-625. https://doi.org/10.1080/09669582.2013.875550

Pocewicz, A., Kiesecker, J.M., Jones, G.P., Copeland, H.E., Daline, J., Mealor, B.A., 2011. Effectiveness of conservation easements for reducing development and maintaining biodiversity in sagebrush ecosystems. Biol. Conserv. 144, 567-574. https://doi.org/10.1016/j.biocon.2010.10.012

R Core, T., 2018. R: A language and environment for statistical computing. R Foundation for Statistical Computing, Vienna, Austria. URL https://www.R-project.org/. https://doi.org/URL https://www.R-project.org/

Reed, M.S., Graves, A., Dandy, N., Posthumus, H., Hubacek, K., Morris, J., Prell, C., Quinn, C.H., Stringer, L.C., 2009. Who's in and why ? A typology of stakeholder analysis methods for 
natural resource management. J. Environ. Manage. 90, 1933-1949. https://doi.org/10.1016/j.jenvman.2009.01.001

599

600

601

602

603

604

605

606

607

608

609

610

611

612

613

614

615

616

617

618

619

620

621

Rissman, A., Bihari, M., Hamilton, C., Locke, C., Lowenstein, D., Motew, M., Price, J., Smail, R., 2013. Land Management Restrictions and Options for Change in Perpetual Conservation Easements 277-288. https://doi.org/10.1007/s00267-013-0091-z

Rissman, A.R., 2013. Rethinking property rights: Comparative analysis of conservation easements for wildlife conservation. Environ. Conserv. 40, 222-230. https://doi.org/10.1017/S0376892913000015

Rissman, A.R., 2010. Designing perpetual conservation agreements for land management. Rangel. Ecol. Manag. 63, 167-175. https://doi.org/10.2111/08-251.1

Rissman, A.R., Lozier, L., Comendant, T., Kareiva, P., Joseph, M., Shaw, M.R., Merenlender, A.M., 2007. Conservation Easements : Biodiversity Protection and Private Use. Conserv. Biol. 21, 709-718. https://doi.org/10.1111/j.1523-1739.2007.00660.x

Rissman, A.R., Owley, J., L'roe, A.W., Morris, A.W., Wardropper, C.B., 2017. Public access to spatial data on private-land conservation. Ecol. Soc. 22. https://doi.org/10.5751/ES-09330220224

Rissman, A.R., Owley, J., L’Roe, A.W., Morris, A.W., Wardropper, C.B., 2017. Public access to spatial data on private-land conservation. Ecol. Soc. 22, 24.

Rowe, G., Frewer, L.J., 2000. Public Participation Methods: A Framework for Evaluation. Sci. Technol. Hum. Values 25, 3-29. https://doi.org/10.1177/016224390002500101

Salafsky, N., Salzer, D., Stattersfield, A.J., Hilton-taylor, C., Neugarten, R., Butchart, S.H.M., Collen, B.E.N., Cox, N., Master, L.L., Connor, S.O., Wilkie, D., 2008. A Standard Lexicon for Biodiversity Conservation: Unified Classifications of Threats and Actions 22, 897-911. https://doi.org/10.1111/j.1523-1739.2008.00937.x

Salomaa, A., Paloniemi, R., Hujala, T., Rantala, S., Arponen, A., Niemelä, J., 2016. Forest Policy 
and Economics The use of knowledge in evidence-informed voluntary conservation of Finnish forests. For. Policy Econ. 73, 90-98. https://doi.org/10.1016/j.forpol.2016.09.004

624

625

626

627

628

629

630

631

632

633

634

635

636

637

638

639

640

641

642

643

644

645

646

Schuster, R., Law, E.A., Rodewald, A.D., Martin, T.G., Wilson, K.A., Watts, M., Possingham, H.P., Arcese, P., 2017. Tax Shifting and Incentives for Biodiversity Conservation on Private Lands. Conserv. Lett. 0, 1-7. https://doi.org/10.1111/conl.12377

Selinske, M.J., Coetzee, J., Purnell, K., Knight, A.T., Lombard, A.T., 2015. Understanding the Motivations, Satisfaction, and Retention of Landowners in Private Land Conservation Programs 8, 282-289. https://doi.org/10.1111/conl.12154

Selinske, M.J., Cooke, B., Torabi, N., Hardy, M.J., Knight, A.T., Bekessy, S.A., 2017. Locating financial incentives among diverse motivations for long-term private land conservation 22 .

Serenari, C., Peterson, M.N., Wallace, T., Stowhas, P., 2017. Private protected areas , ecotourism development and impacts on local people $\hat{a}^{\mathrm{TM}} \mathrm{s}$ well-being: a review from case studies in Southern Chile. J. Sustain. Tour. 25, 1792-1810. https://doi.org/10.1080/09669582.2016.1178755

Sorice, M.G., Donlan, C.J., 2015. A human-centered framework for innovation in conservation incentive programs. Ambio 44, 788-792. https://doi.org/10.1007/s13280-015-0650-z

Sterling, E.J., Betley, E., Sigouin, A., Gomez, A., Toomey, A., Cullman, G., Malone, C., Pekor, A., Arengo, F., Blair, M., Filardi, C., Landrigan, K., Luz, A., 2017. Assessing the evidence for stakeholder engagement in biodiversity conservation. Biol. Conserv. 209, 159-171. https://doi.org/10.1016/j.biocon.2017.02.008

Stolton, S., Redford, K.H., Dudley, N., Bill, W., Corcuera, E., Mitchell, B.A., 2014. The Futures of Privately Protected Areas. IUCN, Gland, Switzerland.

Stroman, D., Kreuter, U.P., 2015. Factors Influencing Land Management Practices on Conservation Easement Protected Landscapes. Soc. Nat. Resour. 28, 891-907. https://doi.org/10.1080/08941920.2015.1024365 
647 Swift, B., Arias, V., Bass, S., Chacón, C.M., Cortés, A., Gutierrez, M., Maldonado, V., Milano, M., 648 Nunes, L., Tobar, M., Sanjinés, V., Solano, P., Theulen, V., 2004. Private lands conservation 649 in Latin America: The need for enhanced legal tools and incentives. J. Environ. Law Litig. 19, 650 85-139.

651 Tengö, M., Hill, R., Malmer, P., Raymond, C.M., Spierenburg, M., Danielsen, F., Elmqvist, T.,

652

653

654

655

656

657

658

659

660

661

662

663

664

665

666

667

668

669

670

671 Folke, C., 2017. Weaving knowledge systems in IPBES , CBD and beyond - lessons learned for sustainability. Curr. Opin. Environ. Sustain. 26, 17-25. https://doi.org/10.1016/j.cosust.2016.12.005

Toomey, A.H., Knight, A.T., Barlow, J., 2017. Navigating the Space between Research and Implementation in Conservation 10, 619-625. https://doi.org/10.1111/conl.12315

United Nations Development Programme (UNDP), 2012. Institutional and context analysis guidance note. Oslo.

van der Hel, S., 2016. New science for global sustainability? The institutionalisation of knowledge co-production in Future Earth. Environ. Sci. Policy 61, 165-175. https://doi.org/10.1016/j.envsci.2016.03.012

Van Fleet, T.E., Kittredge, D.B., Butler, B.J., Catanzaro, P.F., 2012. Reimagining family forest conservation: Estimating landowner awareness and their preparedness to act with the conservation awareness index. J. For. 110, 207-215. https://doi.org/10.5849/jof.11-021

Villamagna, A., Scott, L., Gillespie, J., 2015. Collateral benefits from public and private conservation lands : a comparison of ecosystem service capacities. Environ. Conserv. 42, 204215. https://doi.org/10.1017/S0376892914000393

Wallace, G.N., Theobald, D.M., Ernst, T., King, K., 2008. Assessing the Ecological and Social Benefits of Private Land Conservation in Colorado. Conserv. Biol. 22, 284-296. https://doi.org/10.1111/j.1523-1739.2008.00895.x

WCPA, I., 2019. Guidelines for recognising and reporting Other Effective Area-Based 
672 Conservation Measures. Switzerland.

673 Wright, J.B., 1994. Designing and Applying Conservation Easements. J. Am. Plan. Assoc. 60, 380674 388. https://doi.org/10.1080/01944369408975596

675 
678

679

680

681

682

683

684

685

686

687

688

689

690

691

692

693

694

695

696

697

698

699

700

701

\section{Figure legends}

Figure 1: Global distribution of private land conservation peer-reviewed articles in English,

classified according to the countries where the studies were conducted. Colour classification shows the number of articles per country and was prepared using the geometrical interval method in ArcMap. The geometrical intervals classification is an appropriate method to classify heavily skewed, not normally distributed, data and was used only for visualization purposes.

Figure 2: Barplots showing the ten most frequent topics (i.e. words) occurring in abstracts of peerreviewed articles about private land conservation. Abstracts were divided by the time when the studies were published: (a) before the approval of the Convention on Biological Diversity (CBD) Strategic Plan for Biodiversity 2011-2020 and the Aichi Biodiversity Targets in 2010; (b) after the approval of the CBD Strategic Plan for Biodiversity. Note the differences in the y-axes.

Figure 3: Five most frequent topics (i.e. words) occurring in abstracts of English peer-reviewed articles about private land conservation, classified according to the continents where the studies were conducted. Continents classification followed the United Nations "Standard Country or Area Codes for Statistical Use" (https://unstats.un.org/unsd/methodology/m49/). Note that data from Asia was not displayed due to the small sample size (only one article).

Figure 4: Barplot showing the number of scientific peer-reviewed articles in English addressing different private land conservation policy instruments. Note that a given article can address more than one policy instrument. 
702 Figure 5: Reported stakeholders' engagement in private land conservation scientific peer-reviewed

703 articles in English, shown as two barplots: (a) the number of articles reporting the engagement of

704 none, one, two and three stakeholder sectors (i.e. private, public and civil society) in the research

705 process; (b) the number of articles reporting the engagement of different stakeholders sectors in the

706 research process. Note that a given article can report the engagement of more than one stakeholder

707 sector..

708

709

710 
Figure 1

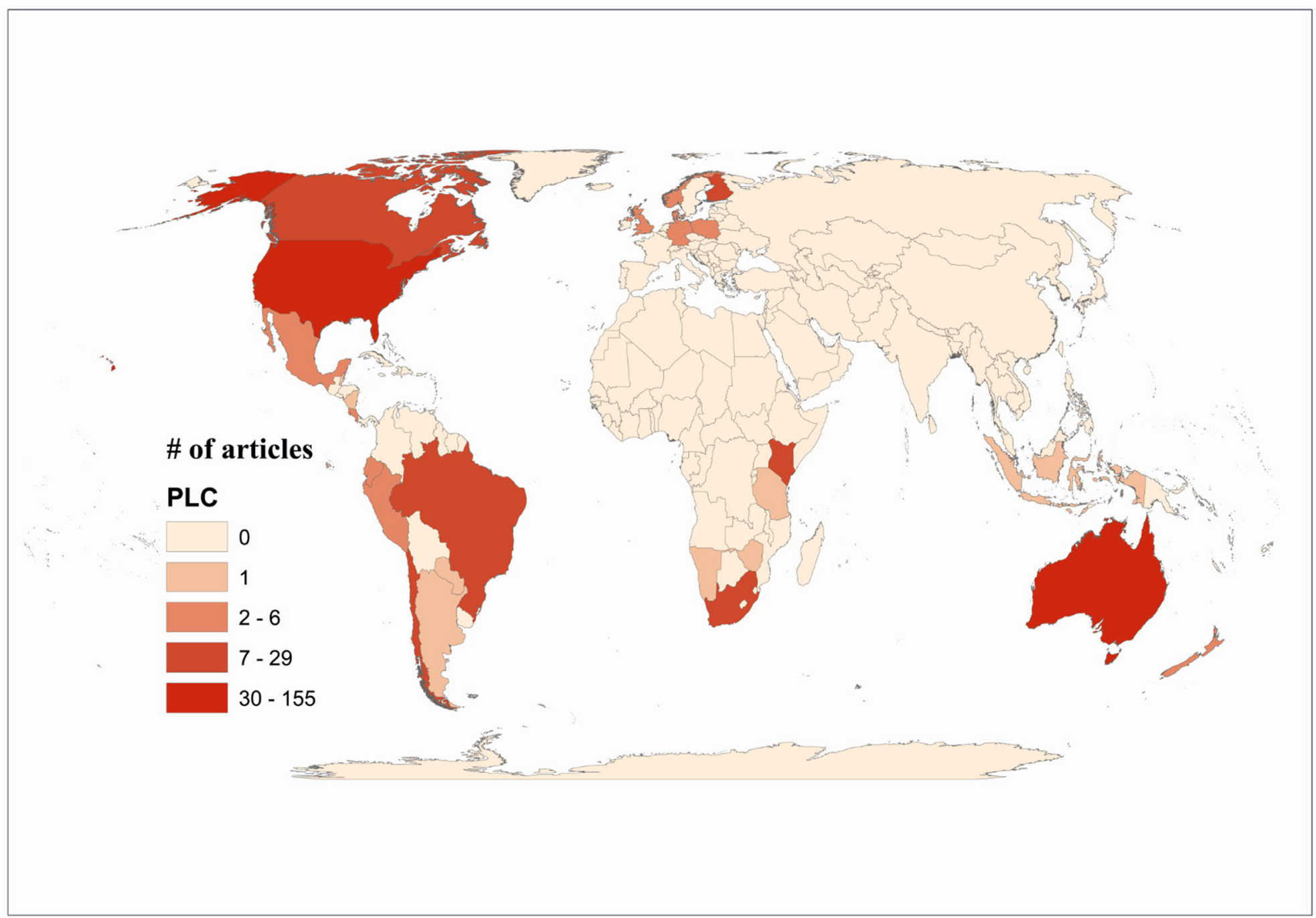


$714 \quad$ Figure 2
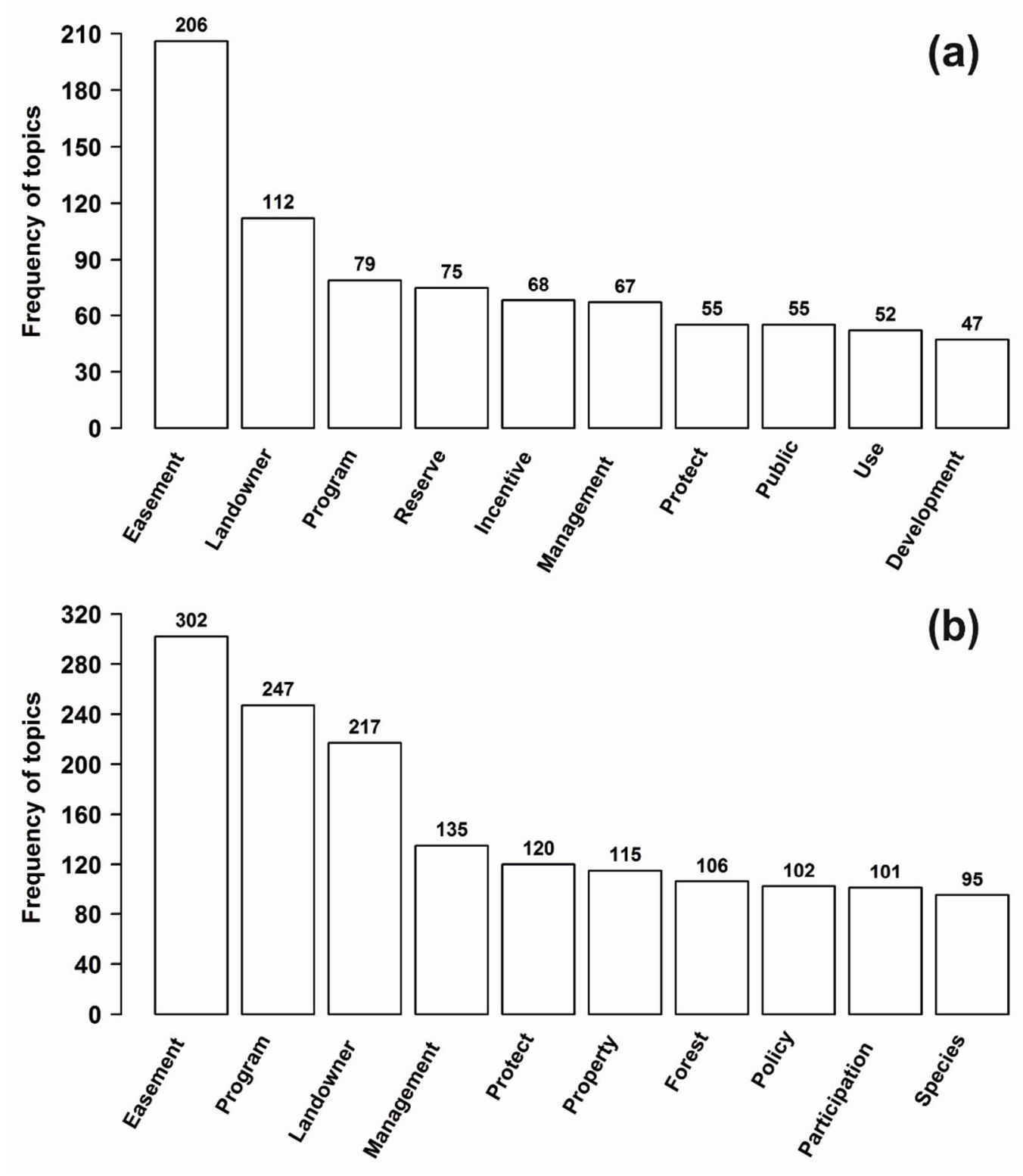


\section{Figure 3}

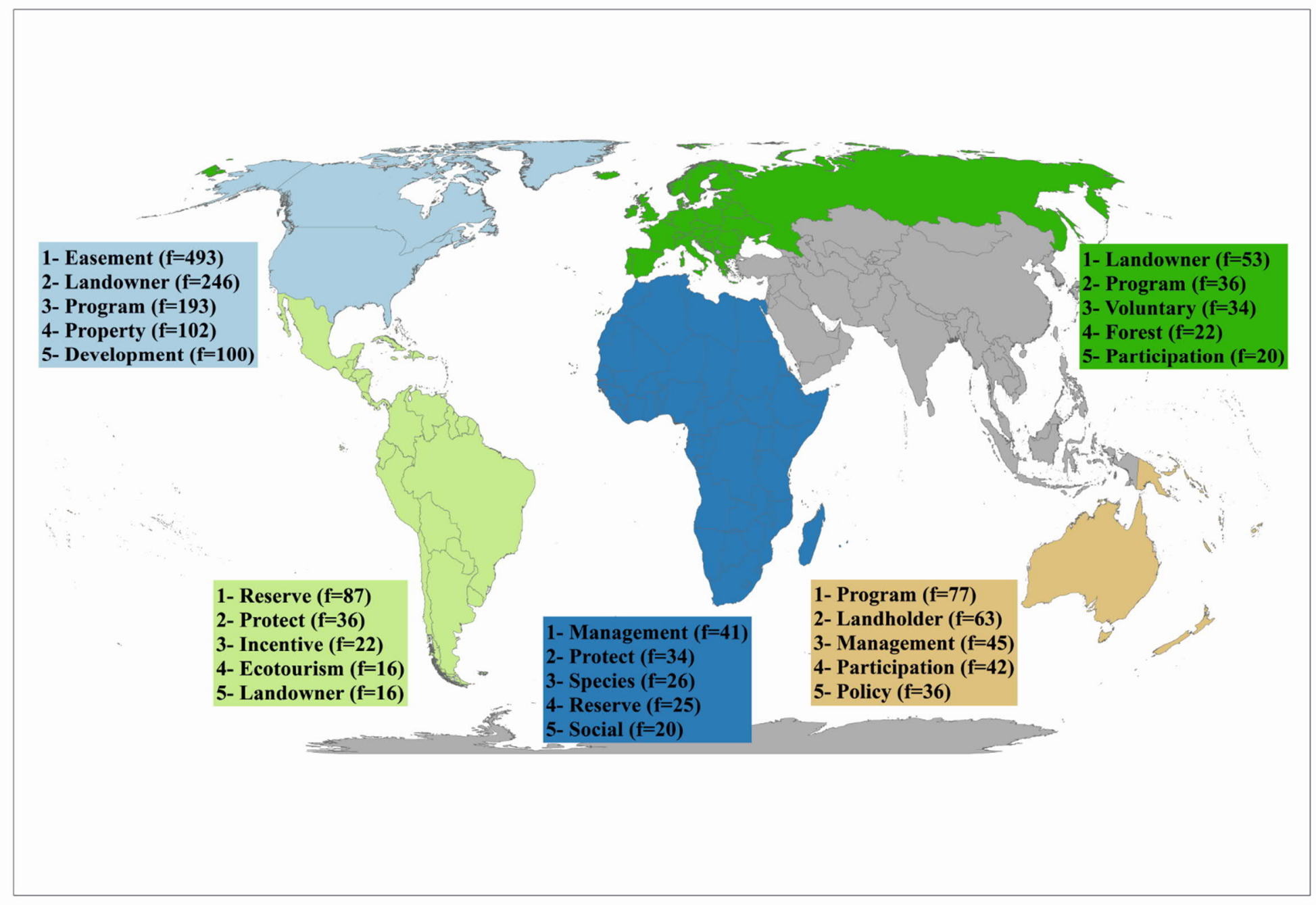




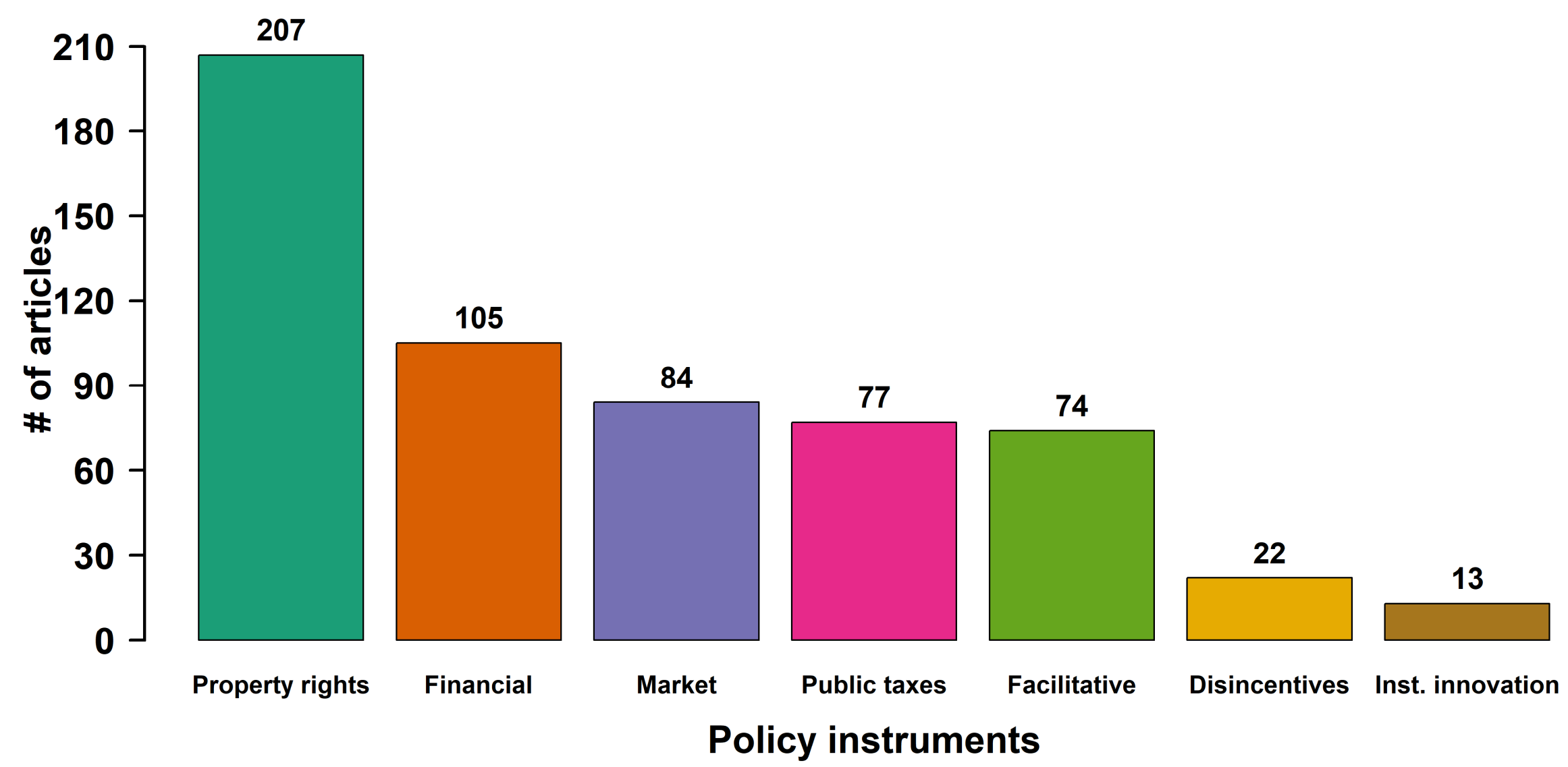


Figure 5

(a)

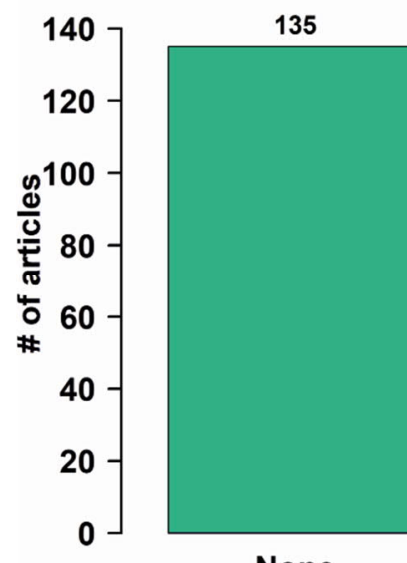

None
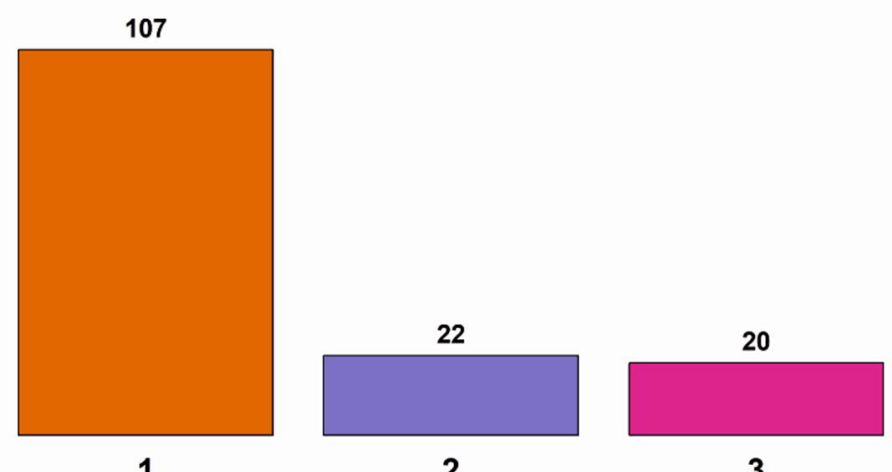

\# stakeholders' sectors

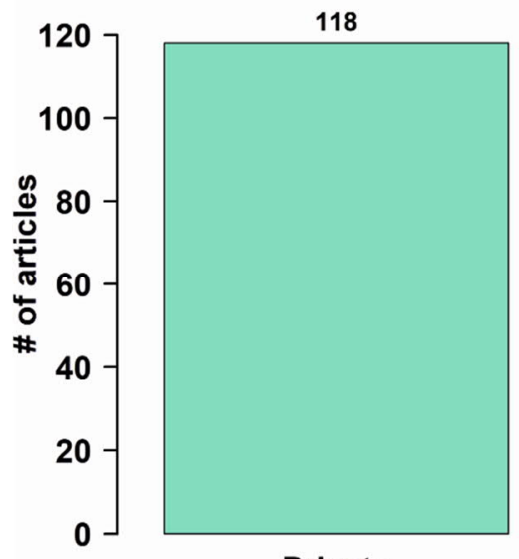

Private

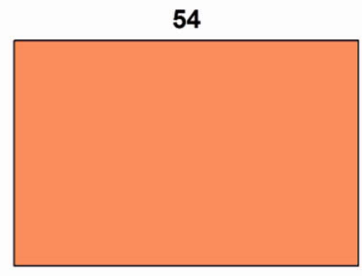

Civil Society takeholders' sectors (b)

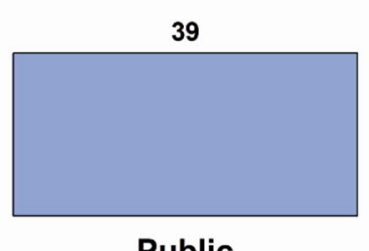

Public 